\title{
Polifonía en educación
}

multicultural: enfoques académicos sobre diversidad y escuela

Carmen Montecinos-Sanhueza carmen.montecinos@pucv.cl Pontificia Universidad Católica de Valparaíso, Chile http://orcid.org/0000-0001-8382-1848

\section{Resumen}

Examinamos el concepto de educación multicultural en investigaciones educativas en Chile. Mediante una revisión de mapeo crítico y análisis semántico de 28 artículos, se identificaron los principales ámbitos y enfoques en educación multicultural en el período 2004-2013. Los resultados evidencian la predominancia de investigaciones en el ámbito indígena, enfoques orientados a las relaciones humanas y del reconocimiento y mantención de identidades socioculturales. La discusión releva la necesidad de ampliar la investigación a otros ámbitos de diversidad cultural, incorporar una perspectiva de justicia social que aborde las desigualdades escolares $y$, finalmente, al desarrollo de investigación educativa aplicada, transformadora y situada.

\section{Palabras clave}

Educación intercultural; justicia social; investigación sobre la educación; diversidad cultural

\begin{abstract}
We examine the concept Multicultural Education in the educational researches in Chile. A review combining critical mapping and semantic analysis of articles identified the main communities and approaches in multicultural education for the last 10 years. The results show the prevalence of researches about indigenous communities and approaches focused on human relationships as well as the recognition and maintenance of sociocultural identities. The discussion raises awareness on the need to expand the research into other culturally diverse communities, to include a perspective of social justice to address the school inequalities. Finally, it encourages the development of applied, transforming and grounded educational research.
\end{abstract}

\section{Keywords}

Cross-cultural education; social justice; research on education; cultural education

Para citar este artículo / To cite this article

Jiménez-Vargas, F. \& Montecinos-Sanhueza, C. (2019). Polifonía en educación multicultural: enfoques académicos sobre diversidad y escuela. magis, Revista Internacional de Investigación en Educación, 12 (24), 105-128. doi: 10.11144/Javeriana.m12-24.peme 


\section{Introducción}

La relación entre diversidad cultural y escuela ha venido cobrando una progresiva relevancia en América Latina desde la década de los noventa, que se expresa en el hecho de que en diversos países de la región ha ido aumentando sistemáticamente la discusión académica y la producción bibliográfica (Ferrão, 2010). En el marco de los esfuerzos que los gobiernos latinoamericanos vienen materializando desde esos años en el desarrollo de políticas educativas inspiradas en la igualdad de oportunidades (Tubino, 2005), la diversidad cultural ha mostrado convertirse en fuente de desigualdad educativa y, por tanto, se ha convertido a su vez en materia de investigación educativa. De esta manera, en el contexto latinoamericano, se consolida el estudio de los efectos que las políticas neoliberales han tenido sobre escenarios educativos caracterizados por su diversidad cultural (Walsh, 2009), reconociendo el valor y el potencial que tiene la escuela en contribuir a disminuir las desigualdades y revertir las formas de exclusión y discriminación que afectan a determinados grupos excluidos y/o desfavorecidos (Gentili, 2011).

En el caso de Chile y de manera congruente con el devenir latinoamericano, las investigaciones en materia de educación intercultural han ido cobrando relevancia académica en los últimos años. No obstante, hasta el momento no se identificaron estudios que permitiesen comprender los ámbitos de interés, los principales enfoques, las omisiones y las brechas. El propósito de este trabajo es el de ofrecer una sistematización que otorga visibilidad y transparencia a la investigación en educación intercultural en Chile, para contribuir a conocer qué tipo de investigación se ha realizado hasta el momento, comprender qué discursos académicos en torno a la interculturalidad subyacen a estas investigaciones y de esta manera, proyectar algunos desafíos para futuras investigaciones en la materia.

Analizar los enfoques de educación intercultural de las investigaArticle description

En este artículo de reflexión, derivado del proyecto de investigación Orientaciones para el diseño e implementación de un programa escolar de acogida para la escolarización de alumnado inmigrante en escuelas chilenas, los autores exploran las investigaciones sobre educación multicultural en Chile e identifican los principales ámbitos de acción y enfoques utilizados por los académicos. démicos consideran que debiese ser el propósito y función social de la educación intercultural. Esto supone una relevancia especial mientras los círculos académicos ejercen un papel central y hegemónico en la producción de conocimiento y en la legitimación por tanto de determinados discursos en torno a la gestión de la diversidad cultural (van Dijk, 2009). A su vez, los discursos académicos tienen la capacidad performativa de definir el "saber oficial" en el ámbito educativo y por tanto, ejercer influencia sobre las políticas educativas y las prácticas cotidianas de las instituciones escolares. Finalmente, nuestra investigación aporta un análisis crítico de los desafíos académicos en materia de investigación y de los temas pendientes de cara a una educación intercultural en clave de justicia social.

El artículo se organiza en cinco apartados. El primero de ellos contextualiza el ámbito de estudio de la sistematización, focalizada en los cambios y diversificación sociocultural que ha habido últimamente en la composición de los estudiantes en las escuelas. El apartado dos presenta la taxonomía conceptual de enfoques de educación intercultural utilizada en nuestro estudio. En el tercer y cuarto apartado se especifican las decisiones metodológicas así como los principales hallazgos. Finalmente, se discuten los resultados con relación a los ámbitos de investigación, a los enfoques predominantes así como a las implicancias para la investigación educativa en materia de educación intercultural. 


\section{Estado actual del sistema educativo chileno}

Pese al impacto de las políticas educativas neoliberales impulsadas en los años ochenta y noventa por homogeneizar el sistema educativo chileno a través de estrategias de segregación escolar (Fardella, 2013a, 2013b), en tensión con las políticas educativas actuales que intentan avanzar en materia de equidad e igualdad de oportunidades, en el transcurso de la última década la composición demográfica de las escuelas se ha vuelto paradójicamente cada vez más heterogénea. Si bien esta transformación requiere una explicación multidimensional que incorpore una amplia gama de fuentes de diversidad escolar - género, orientación sexual, pertenencia étnica, entre otras-, dos factores han contribuido de manera especial a hacer de las escuelas espacios cada vez más diversos (Jiménez \& Fardella, 2015).

El primero de ellos corresponde al aumento de proyectos de integración escolar que ha supuesto el cierre progresivo de escuelas especiales. De acuerdo a los resultados de una investigación reciente, a nivel nacional un cuarenta y cinco por ciento de las escuelas con financiamiento público han incorporado en los últimos años programas de integración escolar para la escolarización de estudiantes provenientes de escuelas especiales (Marfán, Castillo, González \& Ferreira, 2013).

El segundo factor corresponde al metódico incremento de estudiantes inmigrantes al sistema educativo chileno. De acuerdo con cifras oficiales, para el año académico 20161, 61.000 estudiantes inmigrantes están escolarizados en los niveles de educación obligatoria, que se concentran mayoritariamente en escuelas públicas. Si bien esto solo corresponde a $1 \%$ de la matrícula total, actualmente hay escuelas municipales donde la matrícula de estudiantes inmigrantes supera el 50\%. Pese a que desde mediados de los noventa Chile cuenta con un programa de educación intercultural (Ministerio de Educación, 2002; Riedemann, 2008), esta política educativa se orienta exclusivamente a la escolarización de estudiantes pertenecientes a pueblos originarios (Montecinos, 2004), lo que evidencia que a la fecha y pese al desarrollo de una política nacional de estudiantes extranjeros (Mineduc, 2018), sigue pendiente el desarrollo de una política educativa intercultural que vaya más allá del ámbito indígena.

Ante este escenario, en los últimos años ha habido un creciente interés por investigar, en diferentes dimensiones de la realidad educativa, los efectos políticos y las repercusiones escolares que estos cambios tienen para las prácticas cotidianas en nuestras escuelas. No obstante, no hay una manera unívoca de definir e investigar la educación intercultural, razón que justifica mapear las investigaciones en torno a este campo en nuestro país, para develar sus principios, ámbitos de acción e implicancias tanto para el ámbito educativo como para la propia investigación académica.

\section{Conceptualización de la educación intercultural}

Tradicionalmente, la educación intercultural se ha entendido como aquella educación que transcurre en entornos educativos con una diversidad cultural significativa, referida principalmente al origen sociocultural o a la pertenencia étnica de sus participantes. Esta perspectiva corresponde a una aproximación fáctica del término (Giménez-Romero, 2009), pero al mismo tiempo reduccionista (Dietz, 2012), ya que acentúa la coexistencia

1 Datos del Departamento de Extranjería y Migración disponibles en http://www.extranjeria.gob.cl/ 
en un mismo espacio educativo de estudiantes pertenecientes a culturas o países diferentes. Para el caso latinoamericano, la educación intercultural ha sido entendida hegemónica y descriptivamente como etnoeducación, vale decir, como educación indígena (Montecinos, 2004; Romero-Medina, 2010; Walsh, 2009), y solo recientemente ha ido diversificando sus ámbitos de acción para incluir y referir a otros grupos minoritarios, como la cultura sorda (de la Paz \& Salamanca-Salucci, 2009) o las culturas migrantes (Jiménez \& Fardella, 2015; Navas \& Sánchez, 2010; Riedemann \& Stefoni, 2015).

No obstante lo anterior, en la literatura hay consenso en que una aproximación fáctica no grafica adecuadamente la especificidad de lo intercultural en entornos educativos (Essomba, 2006; Lalueza, 2012; Williamson, 2011), ya que estas conceptualizaciones descriptivas y aritméticas de la multiculturalidad plantean la diversidad cultural como una sumatoria de unidades aisladas diferentes (Díaz-de Rada, 2010). En oposición a este enfoque reduccionista, Guillermo Williamson C. (2011) Ilama a poner el acento justamente en las relaciones entre "diversidades" al privilegiar aspectos ideológicos y de poder que están en la base de las interacciones que tienen lugar en escenarios educativos interculturales. En esta línea, Carlos Giménez Romero (2003) sugiere privilegiar el componente normativo de toda educación, vale decir, un acercamiento que resalte las propuestas ideológicas y axiológicas en torno a la gestión de la diversidad cultural (Dietz, 2012).

\section{Enfoques de educación intercultural}

Aun cuando la producción académica en torno a la educación intercultural en el contexto latinoamericano se ha ido configurando como un campo de investigación propio y progresivamente consistente, a la fecha no hay una adecuada sistematización que profundice en las diversas formas de entender la educación intercultural. Para los fines de nuestro mapeo, se utilizará el modelo de enfoques de Christine Sleeter y Carl Grant (2009) que tomaremos como marco interpretativo para sistematizar y analizar la investigación en educación intercultural en Chile. La elección de este modelo se justifica en el siguiente argumento. En Latinoamérica, la educación de grupos sociales excluidos o marginados ha implicado esfuerzos de distintos colectivos y se han desarrollado agendas paralelas para garantizar una educación con equidad y calidad (Williamson \& Montecinos, 2001). Por ejemplo, están movimientos de educación popular con obreros y campesinos, educación intercultural bilingüe con pueblos originarios. A diferencia del desarrollo en Estados Unidos, los proyectos educativos de estos distintos colectivos no han convergido en un movimiento único que proponga avanzar hacia una educación que promueva el reconocimiento y valoración de las diferencias, mayor equidad, participación, pluralismo y justicia social más allá de su grupo en particular. En ausencia de una tipología nacional o latinoamericana que permita comprender las distintas agendas y propuestas que se desarrollan para avanzar hacia una educación intercultural en una sociedad pluralista, se optó por la tipología de enfoques para abordar la educación multicultural propuesta por Christine Sleeter y Carl Grant (2009), desarrollada a partir de una sistematización de la investigación existente principalmente en Estados Unidos a la fecha.

La apropiación de este marco analítico se basa en el supuesto de que tanto en Estados Unidos como en Latinoamérica, y Chile en particular, la educación de grupos sociales excluidos se caracteriza por mecanismos que refuerzan su exclusión y marginalización en la participación escolar, ciudadana y económica. En ambos contextos, el capital cultural y la herencia cultural de estos grupos (por ejemplo, pueblos originarios que están en el 
centro de la educación intercultural bilingüe) son invisibilizados o poco valorados, porque la escuela opera desde una lógica de déficit respecto a lo que esos estudiantes traen a su proceso de escolarización formal. Estas condiciones se traducen en mayores índices de fracaso y deserción escolar en estudiantes indígenas, de los quintiles más bajos, con necesidades educativas especiales. Tanto la educación multicultural como la educación intercultural abordan propuestas para mejorar las oportunidades para el aprendizaje, un compromiso con la creación de escuelas que valoran la diversidad y permiten a todos los estudiantes reconocer sus experiencias en el currículo escolar, y entienden que el reconocimiento y la valoración de la diversidad son claves para el avance en la democratización de la sociedad.

El modelo de Sleeter y Grant (2009) nos permite considerar múltiples aspectos de la identidad social desde los cuales en el sistema educativo se genera discriminación y procesos de exclusión. Los distintos enfoques no permiten entender que para algunos autores abordar esta temática pasa por mejorar la autoestima de los estudiantes y asimilarlos a la cultura dominante, otros enfoques proponen que esto es insuficiente y se requiere abordar temas estructurales que organizan las relaciones sociales con base en jerarquías y binarios (hombre-mujer; heterosexual-homosexual; indígena-no indígena; con discapacidad-sin discapacidad). Prueba de ello es el hecho de que lo que comenzó justamente como un análisis de la investigación en educación multicultural en Estados Unidos a finales de los ochenta, hoy corresponde a un sólido modelo de cinco enfoques para el análisis de la raza, la clase social y el género en el ámbito de las prácticas educativas (Sleeter \& Grant, 2009).

Ahora bien, la elección de este modelo no está exenta de controversias. En primer lugar, por el hecho de que al ser una perspectiva de tradición anglosajona, lo "intercultural" queda aparentemente invisibilizado — cuando no negado - como significante. En segundo lugar, ya que el hecho de considerar principalmente experiencias educativas en clave migratoria impide hacer una lectura directa hacia la experiencia de otros grupos minoritarios relevantes para nuestro contexto de estudio, como es el caso del lugar de las minorías indígenas en el ámbito educativo y su relación con estudiantes no indígenas. En consecuencia y como forma de evitar un uso inadecuado del modelo, se han incluido desarrollos latinoamericanos en torno al mismo fenómeno que conviene tener en consideración (Mato, 2005; Tubino, 2005; Walsh, 2009), puesto que permitirán hacer una lectura más situada del fenómeno, lo cual evita hacer extrapolaciones que puedan conducir a análisis reduccionistas, forzados y/o estériles, al enseñar a los excepcional y culturalmente diferentes.
Este primer enfoque de educación intercultural supone que para gestionar la diversidad cultural, la escuela debe implementar determinados "ajustes" a su modelo educativo tradicional. Estos ajustes consisten en la implementación de estrategias compensatorias que permitan hacer frente a los vacíos existentes conocimientos, habilidades, valores y/o procedimientos- en los estudiantes de grupos minoritarios.

En la medida en que estos mecanismos compensatorios no tienen únicamente un sentido aditivo, sino que además apartan los elementos culturales que entorpecen a los estudiantes acceder exitosamente al currículum escolar, queda en evidencia el sentido asimilacionista de este enfoque. Desde este enfoque, por tanto, los procesos de asimilación vendrían a nivelar e igualar las oportunidades educativas, lo cual genera las condiciones para que los estudiantes minoritarios puedan apropiarse con éxito del currículum oficial de la escuela (Gorski, 2006, 2009).

\section{Relaciones bumanas}

Corresponde a un segundo enfoque para el que la diversidad cultural en la escuela es un ámbito que debiese estar orientado al mejoramiento de la convivencia escolar y privilegiar la promoción de interacciones armónicas entre los actores educativos. Es un enfoque que ve en la diversidad cultural una oportunidad para el desarrollo de actitudes y valores - como tolerancia, respeto y no discriminación-que en conjunto contribuyan al logro de relaciones humanas menos discriminatorias y más respetuosas con los derechos individuales (Montecinos, 2011).

Si bien este enfoque implica un avance respecto a la ecuación déficit-compensación del modelo anterior, continúa evidenciando de manera subyacente la supremacía de la cultura hegemónica con relación a las culturas minoritarias, ya que la experiencia escolar global permanece mayoritariamente inalterada (Jiménez, 2012). Esto hace que el enfoque de relaciones humanas corresponda a un modelo liberal de educación intercultural centrado en el reconocimiento de las libertades individuales (Jenks, Lee \& Kanpol, 2001), pero ante todo relacional (Walsh, 2009). El excesivo protagonismo de la noción de la tolerancia como dispositivo de ecualización cultural, mantiene intactas las lógicas de dominación y las desigualdades que se producen y reproducen en el espacio escolar (Walsh, 2005).

\section{Estudios de grupo único}

Se caracterizan por centralizar la educación intercultural en un grupo minoritario en particular, al aumentar el grado de conocimiento sobre él así como de las relaciones que este establece con otros grupos dominantes en el espacio escolar. 
Ya que el foco de atención son las diferentes situaciones de discriminación y opresión social que históricamente han afectado - y condicionado- a estos grupos minoritarios, los estudios de grupo único inauguran una primera modalidad de educación intercultural crítica (Jenks, Lee \& Kanpol, 2001), en la medida en que al superar las limitaciones de los enfoques asimilacionistas y folkloristas, han comenzado a reconocer el papel que la escuela desempeña en el desarrollo de sociedades más justas (Dover, 2009; Sleeter, 2013). Al igual que para el caso de las relaciones humanas, los estudios de grupo único pueden fácilmente traducirse en expresión de un modelo relacional de interculturalidad (Walsh, 2009), pues aumentar el conocimiento y la comprensión de grupos minoritarios no altera necesariamente la asimetría de las relaciones establecidas; las reglas del juego siguen inspiradas en principios neoliberales que pueden terminar por implementar modalidades funcionales de interculturalidad centradas en la acción afirmativa y la discriminación positiva (Tubino, 2005).

\section{Educación multicultural}

Constituye una segunda variante de educación intercultural crítica, con un mayor compromiso político que el enfoque de grupo único. Esto se explica por el hecho de que la escuela apuesta por una transformación global de sus procesos educativos, al entregar condiciones educativas equitativas - no necesariamente igualitarias - y apostar por la igualdad de condiciones de todos los grupos/colectivos presentes en la escuela (Montecinos \& Ríos, 1999). Este enfoque hace un llamado a que el profesorado reconozca el trabajo en torno a temas de poder y privilegio en el aula como parte de sus prácticas educativas, de manera que pueda desestabilizar la hegemonía cultural — de clase, de etnia, de capacidades - vehiculizada a través de los contenidos, las actividades y las evaluaciones habitualmente implementadas en la escuela. La educación multicultural es en definitiva un llamado a enseñar sobre y en contra de la injusticia, y garantizar de esta manera la equidad educativa para todos los estudiantes (Grant \& Sleeter, 2006).

\section{Educación multicultural y reconstruccionista social}

La perspectiva reconstruccionista corresponde a la versión más sofisticada de educación intercultural que ubica la escuela como un lugar estratégico para desarticular el modelo educativo imperante y para estimular entre sus actores la reflexión crítica en torno a formas posibles de cambio, lo cual contribuye a fin de cuentas al desarrollo de una ciudadanía activa y democrática (Banks, 2004), elementos ya presentes en el enfoque anterior. Sin embargo, para alcanzar tales propósitos, desde una perspectiva reconstruccionista social, la escuela no puede circunscribir su labor dentro del perímetro escolar, sino que debe actuar de manera ecológica con las comunidades de base y los entornos familiares (Bronfenbrenner, 1987), para convertirse en un escenario social al servicio de la formación de estudiantes con compromiso social. En la medida en que corresponde a un enfoque que aboga por la transformación de las estructuras, instituciones y relaciones sociales en el contexto educativo, se corresponde con una perspectiva empoderadora de la educación intercultural (Dietz \& Mateos, 2013) con un fuerte y claro compromiso por una educación para la justicia social (Sleeter, Montecinos \& Jiménez, 2016).

Las características clave de una educación para la justicia social (Sleeter, Montecinos \& Jiménez, 2016) son cuatro: a) situar a las familias y las comunidades dentro de un análisis de las desigualdades estructurales $y$, de esta forma, evitar explicaciones educativas basadas únicamente 
en características individuales de los estudiantes o a partir de su pertenencia cultural; b) desarrollar relaciones de reciprocidad con estudiantes, sus familias y comunidades, para promover de esta forma relaciones más horizontales y con mayor grado de conocimiento mutuo entre docentes y estudiantes; c) enseñar con altas expectativas, para superar las creencias asociadas al déficit cultural y desarrollar experiencias educativas estimulantes y motivantes para todos los estudiantes; finalmente, d) crear un currículum inclusivo, que integre no solo el saber oficial sino las diferentes voces y perspectivas tradicionalmente silenciadas en el ámbito educativo.

\section{Método}

Con el propósito de analizar los ámbitos y enfoques de educación intercultural presentes en las investigaciones realizadas en Chile entre 2004 y 2013, se tomaron las siguientes decisiones metodológicas:

a. Acotar la búsqueda de artículos a las 5 principales bases de datos de publicación en Chile: Latindex, Redalyc, SciELO, Scopus y WOS-Thomson Reuters. Junto con esta elección de bases de datos, la búsqueda se limitó a publicaciones que reportaran resultados de investigaciones empíricas, lo que supuso la exención de estudios de circulación más restringida como capítulos de libros, manuscritos no publicados, informes técnicos o de políticas públicas. Restringir el corpus a estas bases de datos garantiza además que las investigaciones han sido sujetas a procesos de evaluación de pares y que cumplen por tanto con los criterios y estándares consensuados por la comunidad de investigadores en educación.

b. Seleccionar investigaciones centradas en el contexto educacional chileno, y enmarcadas en los períodos de escolarización obligatoria (educación primaria y secundaria), pues el acento de la investigación está puesto justamente en delimitar dentro de los enfoques, la función social que cumple la escuela en materia de educación intercultural.

c. Definir y utilizar palabras clave y combinaciones entre ellas (interculturalidad, diversidad, escuela, educación intercultural, entre otras), para indagar en los motores de búsqueda e identificar los artículos para su selección con base en los criterios señalados.

En términos generales, el trabajo analítico realizado corresponde a una revisión de mapeo crítico que intersecta elementos de un mapping review con elementos propios de un critical review (Grant \& Booth, 2009). Del primero se rescata el propósito de categorizar la literatura existente e identificar posibles vacíos y lagunas sobre el fenómeno de estudio, en nuestro caso, a partir de los enfoques del modelo de Christine E. Sleeter y Carl A. Grant (2009); del segundo se rescata el propósito de ir más allá de una mera descripción del estado del arte sobre el fenómeno de estudio e incluir diferentes grados de análisis y posibles innovaciones conceptuales, en nuestro caso sobre la investigación en educación intercultural en Chile.

Operativamente, a partir de un análisis semántico de contenido (Flick, 2009) se examinaron los diferentes apartados de los artículos en los cuales estuviesen plasmados los argumentos para impulsar la educación intercultural en las escuelas (introducción, planteamiento del problema, marco teórico, resultados y discusiones) y así extraer todo el material textual para los fines analíticos de este trabajo. La selección del material y el proceso de 
codificación fueron sometidos a un ejercicio de contrastación por parte de los investigadores, para contar con una triangulación intersubjetiva de los datos. A través de un proceso de codificación abierta (Pidgeon \& Henwood, 1997), se construyeron finalmente 3 categorías centrales que son las que se describen en los apartados ámbitos, enfoques e implicancias. El corpus final se compuso de 28 artículos seleccionados con base en los criterios ya descritos (anexo 1). Adicionalmente, se consideraron 59 referencias que no formaron parte del análisis, pero posibilitaron sentar las bases conceptuales y los marcos comprensivos de interpretación.

\section{Resultados}

Hemos organizado los resultados en dos apartados: el primero corresponde a un mapeo descriptivo que caracteriza los principales ámbitos en educación intercultural, mientras que el segundo ofrece un análisis crítico de los principales enfoques en educación intercultural.

\section{Mapeo descriptivo de ámbitos en educación intercultural}

La revisión documental evidencia la presencia de tres ámbitos hegemónicos en educación intercultural: ámbito indígena, ámbito migratorio y ámbito discapacidad².

\section{Ámbito indígena}

De las 28 investigaciones, 21 componen el ámbito indígena y abordan la educación intercultural desde la perspectiva de/sobre algún pueblo originario de Chile. Corresponden al 75\% del total. En esta categoría encontramos a su vez dos subcategorías: investigaciones centradas en la etnia mapuche y aquellas centradas en etnias altiplánicas.

De las 21 investigaciones de la categoría indígena, nueve de ellas conforman un foco en la sistematización de conocimientos y saberes propios de la cultura mapuche que, de acuerdo a las investigaciones, debiesen formar parte de los contenidos curriculares impartidos por las escuelas (Almendra-Soto, Peña-Cortés \& Rojas-Maturana, 2011; Quilaqueo-Rapimán, 2006, 2012; Quilaqueo-Rapimán \& Quintriqueo, 2007, 2010; Quilaqueo \& San Martín, 2008; Quilaqueo, Quintriqueo \& San Martín, 2011; Quintriqueo \& Maheux, 2004; Quintriqueo \& Torres, 2013).

2 Hay un cuarto enfoque. Por el hecho de estar compuesto por un único artículo y sobre un ámbito inespecífico, no corresponde a un ámbito hegemónico.
También desde el ámbito mapuche, los desarrollos de Nolfa Ibáñez (2010), Aldo Olate V. y Marisol Henríquez B. (2010), Segundo Quintriqueo y Margaret McGinity-Travers (2009) e Ilich Silva-Peña, Karina Bastidas-García, Luis Calfuqueo-Tapia, Juan Díaz-Llancafil y Jorge Valenzuela-Carreño (2013) abordan los alcances de la educación intercultural. Sin embargo, este segundo foco privilegia el estudio de las actitudes que diferentes actores del sistema educativo presentan hacia determinados ámbitos de la escolarización por encima de otros factores implicados en la gestión escolar de la diversidad cultural.

Un tercer foco específico de investigación dentro del ámbito mapuche es el trabajo en torno a los efectos y/o la valoración que diferentes actores educativos hacen de los programas de educación intercultural bilingüe (Forno, Álvarez-Santullano \& Rivera, 2009; Quilaqueo \& Quintriqueo, 2008; Rother, 2005; Williamson, Pérez, Collia, Modesto \& Raín, 2012). Si bien estos programas actúan como encuadre de las investigaciones, como se podrá observar cada una de ellas presenta una mirada particular y resalta determinados aspectos sobre otros.

La sistematización de metodologías de enseñanza de la lengua mapuche se constituye en otro ámbito de investigación de la relación entre educación intercultural y el Programa de Educación Intercultural Bilingüe, PEIB (Quidel-Calitraf, 2011).

El trabajo de Sandra Becerra-Peña y Víctor FloresCantero (2011) corresponde finalmente al quinto foco, el cual profundiza en la existencia de fenómenos de desgaste docente en contextos educativos con estudiantes mapunches.

Los trabajos de Ana María Carrasco-Gutiérrez y Vivian Gavilán-Vega (2012) y Ramiro Catalán (2013) abordan también el tema de la educación intercultural en clave indígena, pero desde la perspectiva altiplánica en el norte de Chile. Sus trabajos abordan los efectos que tanto la educación -en términos históricoscomo la implementación de los programas de educación intercultural —en la actualidad - han tenido en el mantenimiento de las identidades y los referentes socioculturales de los estudiantes indígenas de comunidades aimara y atacameña, respectivamente.

\section{Ámbito migratorio}

Cinco investigaciones forman parte de la categoría ámbito migratorio. Estos estudios versan sobre alguna temática vinculada con el proceso de escolarización de estudiantes extranjeros. Corresponden al $18 \%$ del total de las investigaciones pesquisadas.

Las investigaciones de Leandro Navas-Martínez, Francisco Pablo Holgado-Tello y Alejandra SánchezBravo (2009), Leandro Navas-Martínez y Alejandra Sánchez-Bravo (2010) así como Alejandra Sánchez B., 
Leandro Navas M. y Pablo Holgado T. (2013) componen un primer núcleo temático. Estos tres trabajos se centran en analizar las actitudes que estudiantes de pedagogía presentan hacia los fenómenos migratorios, su relación con los contextos educativos y la educación intercultural propiamente tal.

El segundo núcleo temático está compuesto por los estudios de Kerstin Hein (2012) y María Emilia Tijoux (2013) que, desde una perspectiva cualitativa de investigación y con participantes del sistema escolar, abordan las experiencias de transición entre la escuela y el mundo laboral de los inmigrantes en el primer caso, y las experiencias de violencia simbólica — racismo y xenofobia- que protagonizan estos estudiantes para el segundo caso.

\section{Ámbito de discapacidad}

Contempla un estudio que aborda la experiencia de la cultura sorda en la escuela y da lugar a la categoría ámbito de discapacidad. Corresponde al 3,7\% del total de las investigaciones.

El trabajo desarrollado por María Victoria de la Paz y Marcelo Salamanca-Salucci (2009) ofrece un lúcido análisis de las prácticas escolares en contextos educativos con presencia de estudiantes sordos. Por medio de entrevistas a diez miembros de dos asociaciones de sordos, se aprecia que al igual como ocurre con otro tipo de minorías socioculturales - las indígenas, inmigrantes u otras - el estudiante perteneciente a la cultura sorda es protagonista de episodios sistemáticos de adaptación forzosa y asimilación a la cultura hegemónica, a través de procesos que priorizan la oralidad y la escucha como formas comunicativas.

\section{Ámbito inespecifico}

Finalmente, una investigación que si bien aborda temáticas de diversidad cultural, no aclara el foco específico de trabajo. Esta es la razón por la cual compone la categoría ámbito no especificado. Corresponde al 3,7\% de las investigaciones. Focalizado en la forma en que los docentes conceptualizan y valoran la diversidad en la escuela, el estudio instrumental de caso de Rosa Zapata (2011), que incluyó encuestas a 42 profesores egresados y entrevistas a 7 profesores formadores, evidencia que ambos grupos de profesores muestran actitudes positivas y sensibles hacia la diversidad en la escuela y hacia la promoción de un enfoque intercultural.

\section{Análisis critico de enfoques de educación intercultural}

Al analizar las investigaciones globalmente hablando —vale decir, el corpus de 28 investigaciones-, queda en evidencia que no existe un uso unívoco y consensuado en torno a educación intercultural, sino más bien un uso polifónico y polisémico del término. Si bien esto puede deberse a la naturaleza vaporosa del concepto que complejiza el acto de operativizar qué significado hay detrás de una educación intercultural, lo cierto es que en términos generales las investigaciones no problematizan mayormente el uso del término, y caen muchas veces en el solapamiento conceptual entre la dimensión fáctica y la normativa (Giménez, 2009), entre educación multicultural y educación intercultural como si fuesen fenómenos indistintos y términos reemplazables. Aun cuando desde nuestro punto de vista sí es posible establecer diálogos entre las diferentes tradiciones (latinoamericana, anglosajona y europea) y sus usos, sostenemos que ello no justifica un posicionamiento desinformado y acrítico de estas tradiciones, sus contextos de origen y sus desarrollos e implicancias actuales. 
El análisis de los documentos evidencia la existencia de dos enfoques hegemónicos en educación intercultural: (1) reconocimiento y mantención de identidades socioculturales y, (2) promoción de relaciones interculturales. Si bien los análisis han demostrado que cada uno de estos enfoques presenta sus respectivas líneas argumentativas en torno a los propósitos de la educación intercultural, ambos constituyen enfoques funcionales (Tubino, 2005) y liberales (Jenks, Lee \& Kanpol, 2001) de educación intercultural. Esto ya que aun cuando plantean la necesidad de implementar reformas y cambios para mejorar las trayectorias educativas de estudiantes de grupos minoritarios, no necesariamente abogan por una reformulación estructural de las posiciones y las oportunidades educativas con relación a los estudiantes pertenecientes a grupos minoritarios.

\section{Reconocimiento y mantención de las identidades socioculturales}

El reconocimiento y la mantención de las identidades socioculturales de estudiantes corresponden a dos principios que aparecen de manera recurrente en las investigaciones revisadas, y constituyen una de las principales funciones de la educación intercultural. Aun cuando su alusión en las investigaciones se hace con diferentes énfasis, aparece en 16 de las 28 investigaciones analizadas. Esto demuestra que lo relativo a la identidad sociocultural es una inquietud académica que cruza transversalmente los diferentes ámbitos de estudio —indígena, migratorio y discapacidad-, pero con diferentes grados de profundidad. Pese a esta transversalidad, el ámbito indígena (62\%) es en donde aparece con mayor fuerza la educación intercultural enfocada al tema identitario; el principal argumento del discurso académico es el hecho de que las escuelas no promueven adecuadamente el mantenimiento cultural de estudiantes indígenas, más bien, lo contrario, lo obstaculizan. Las investigaciones sugieren que en la actualidad, las escuelas debiesen rediseñar su oferta educativa de manera que los procesos de enseñanza y aprendizaje contribuyan a dar mayor visibilidad a las culturas minoritarias y mayor representatividad cultural en el currículum escolar. Lo anterior se evidencia en la siguiente viñeta:

El conjunto de contenidos y principios que aquí identificamos, en relación con las categorías de conocimientos sobre la relación de parentesco deseables de transmitir a las nuevas generaciones, constituyen aspectos importantes en el propósito de auto-identificación y reidentificación del niño mapunche. La reidentificación es entendida como un aprendizaje de la pertenencia cultural, social y étnica, a través de procesos de escolarización que considere el patrimonio cultural mapunche. Los antecedentes aportados por la investigación ponen en evidencia que los padres y miembros de la comunidad desean que la escuela asuma una parte de la responsabilidad en la transmisión de contenidos educativos basados en el conocimiento propio del niño mapunche en el medio escolar (Quintriqueo \& Maheux, 2004, p. 86).

El fragmento muestra que la tensión entre la pérdida progresiva de la identidad indígena y los esfuerzos educativos por contribuir al mantenimiento cultural, se focaliza en las investigaciones en diversas dimensiones de la identidad sociocultural: la epistemología, los saberes, las tradiciones y la lengua. Todas estas dimensiones requieren, de acuerdo al discurso académico, ser incorporadas al currículum escolar con el objetivo de que los estudiantes pertenecientes a grupos indígenas no vean debilitada su identidad cultural. 
Aun cuando el ámbito indígena es el que con mayor consistencia evidencia una educación intercultural orientada a la dimensión identitaria, el ámbito de discapacidad otorga igualmente un lugar protagónico a este propósito; en este se define a estudiantes con discapacidad auditiva como pertenecientes a una cultura propia que —al igual que otras culturas minoritarias - debe ser reconocida y representada en el espacio educativo:

No debemos olvidar que al ser la mayoría de los Sordos hijos de padres oyentes y ser los adultos Sordos quienes transmiten su cultura, la escuela juega un rol fundamental como vehículo de transmisión cultural (...) Es a través de la Educación Intercultural Bilingüe que ellos podrán recibir una educación de equidad y calidad como nuestra Constitución lo menciona. Sin embargo, para lograr esto, antes deben ser reconocidos y aceptados como una comunidad socio-lingüística con una cultura distintiva, cuyos elementos culturales les son propios y los lleva a conformar su propia comunidad. Al conocerse su cultura y los elementos que la componen, estos se podrán incluir en el currículum y empezar, al fin, a ofrecerles una educación que los considere como los sujetos distintivos que son (De la Paz \& Salamanca-Salucci, 2009, p. 48).

De esta manera, tanto el ámbito indígena como el de discapacidad evidencian el rechazo a la lógica asimilacionista de la escuela tradicional, así como la defensa de una educación intercultural que reconozca la importancia que los procesos de construcción identitaria tienen en el desarrollo de una pedagogía culturalmente relevante (Peña-Sandoval, 2015). Sin embargo, nuestro análisis demuestra que pese a la implementación de acciones de mayor visibilización de las culturas minoritarias, así como al desarrollo de medidas de acción afirmativa y discriminación positiva (Lalueza, 2012), este enfoque identitario no supone alterar de manera significativa el funcionamiento hegemónico de la cultura escolar predominante, propósitos centrales de los enfoques más integrales y sofisticados de nuestro modelo utilizado ${ }^{3}$. El hecho de que exista una mayor presencia, conciencia y visibilidad de la cultura mapuche y la cultura sorda no implica necesariamente un debilitamiento y cuestionamiento de la cultura dominante, lo que a fin de cuentas no afecta las posiciones y relaciones de poder interculturales en el contexto educativo. Como plantean los enfoques multicultural y multicultural reconstruccionista social, para que ello ocurra debe haber un compromiso explícito e intencionado por develar y deconstruir las dinámicas de poder que predominan en contextos educativos monoculturales (Sleeter \& Grant, 2009), y de esta manera instituir un nuevo lugar a las culturas minoritarias presentes en el contexto escolar.

\section{Mejoramiento de las relaciones interculturales}

En 20 de las 28 investigaciones se argumenta que la educación intercultural debería ponerse al servicio de promover mejores relaciones entre estudiantes de la sociedad mayoritaria y estudiantes de culturas minoritarias. Las formas de concreción de esta mejora adoptan diversas variantes; las más recurrentes son aquellas que privilegian el desarrollo de espacios de comunicación y conocimiento cultural, así como aquellas que destacan el trabajo pedagógico en torno a valores como el respeto, la tolerancia y la no discriminación.

El hecho de que la educación intercultural apunte al mejoramiento de dimensiones relacionadas con el ámbito de la convivencia escolar,

3 Educación multicultural y educación multicultural reconstruccionista social. 
demuestra que a diferencia de una educación intercultural centrada en el reconocimiento y mantención de la identidad cultural, una educación intercultural prorrelaciones interculturales contempla no solo el trabajo con estudiantes minoritarios, sino con la totalidad de los estudiantes de una comunidad educativa. Esto es relevante ya que no solo demuestra un distanciamiento de las maneras más básicas de entender la educación intercultural —enfoque compensatorio y en algunos casos los estudios de grupo único, por ejemplo- (Sleeter \& Grant, 2009), sino al mismo tiempo un acercamiento a los nuevos lineamientos ministeriales para el desarrollo de comunidades escolares inclusivas (Ministerio de Educación, 2016), así como a las orientaciones para la inclusión educativa de estudiantes extranjeros (2017).

Las ideas nucleares de este enfoque se observan sin embargo mayoritariamente en el ámbito indígena, lo que se refleja en el posicionamiento del siguiente discurso:

El propósito es que el enfoque pedagógico intercultural se replique en el medio escolar con alumnos de ascendencia mapuche y no mapuche, para permitir una interacción desde los contenidos de la cultura occidental y mapuche. Es una educación que aspira a formar sujetos capaces de descubrir las diferencias, reconocerlas y comprenderlas desde un enfoque relacional de las culturas (Tzvetan Todorov, 1982; Dominique Schnapper, 1998; Segundo Quintriqueo, 2007, citados en Quilaqueo \& Quintriqueo, 2008, p. 93).

La anterior viñeta evidencia la preocupación que las interacciones tienen en los contextos educativos con presencia de estudiantes indígenas, siendo esencial que estas permitan trabajar en torno a las diferencias de manera que posibilite la comprensión mutua entre estudiantes. El diálogo intercultural aparece en consecuencia como un elemento central, siendo la finalidad de este el desarrollo de actitudes positivas hacia las diferencias socioculturales de los estudiantes. Corresponde a un enfoque por tanto centrado en el desarrollo de estrategias de contacto (Essomba, 1999), esto es, intervenciones educativas que aproximen los diferentes colectivos, que estimulen el conocimiento mutuo y que apuesten por combatir la formación de prejuicios. A diferencia del enfoque centrado en el reconocimiento y la mantención de las identidades socioculturales, el mejoramiento de las relaciones interculturales aparece en las investigaciones como un propósito de educación intercultural que no se conecta necesariamente con la dimensión didáctica de la escolarización. Esto es relevante ya que da cuenta de un enfoque que no permea todas las dimensiones de los procesos educativos, sino que recae en el trabajo en ciertos ámbitos y con la participación de ciertos actores escolares.

En el ámbito de la inmigración también es posible identificar discursos que se mueven en esta línea, que demuestran que no es un propósito que se circunscriba exclusivamente al ámbito indígena. En este ámbito, la educación intercultural se percibe como una oportunidad para enriquecer la convivencia escolar a través del desarrollo de disposiciones y actitudes pluralistas y comprensivas hacia los estudiantes inmigrantes:

Es evidente que se requiere una política educativa multicultural que favorezca la aceptación de la pluralidad de culturas como factor de enriquecimiento para todo el entorno socioeducativo y de prevención frente a estereotipos y actitudes etnocéntricas. Existen diversas medidas que intentan responder a la diversidad cultural del estudiantes, creemos que una iniciativa pertinente es la que se manifiesta en el modelo intercultural que asume 
y potencia la presencia de la pluralidad como elemento enriquecedor y necesario para la convivencia y el desarrollo de todos los individuos como miembros competentes de su comunidad (María Teresa Aguado-Odina, 2002, citada en Navas-Martínez, Holgado-Tello \& Sánchez-Bravo, 2009, p. 46).

De esta manera, se puede ver que el mejoramiento de las relaciones humanas en los contextos escolares constituye una dimensión de primer orden a la hora de conceptualizar la educación intercultural. El trabajo en torno a la discriminación, a la desmitificación de estereotipos y la implementación de estrategias de contacto constituye los ejes articuladores para el aumento del reconocimiento cultural entre los estudiantes. Nuestro análisis evidencia que si bien esta dimensión es necesaria, por sí sola es insuficiente ya que —al igual que el reconocimiento identitario- corresponde a un enfoque que no tiene la fuerza argumentativa necesaria para hacer de la escuela un espacio a partir del cual subvertir significativamente el establishment escolar (Zeichner, 2010) de desigualdad educativa que afecta a estudiantes de grupos minoritarios. El análisis crítico de esto evidencia a su vez que esta perspectiva fragmentada de educación intercultural no es consistente con uno de los principales mandatos ministeriales, a saber, que la educación intercultural no solo permee todo el currículum escolar, sino que además sea el principio rector de todo proyecto educativo institucional (Ministerio de Educación, 2007).

\section{Discusiones}

El análisis crítico de la producción académica en torno a la educación intercultural en Chile ha permitido caracterizar los ámbitos de acción y los enfoques predominantes en la materia. Si bien en los apartados correspondientes hemos analizado parte de las implicancias que tiene la existencia de una educación intercultural orientada preferentemente a lo indígena y migratorio, así como enfocada en lo identitario y relacional, hay algunos análisis adicionales que conviene incorporar a modo de reflexiones para promover nuevas discusiones. Conviene advertir que el presente estudio se basa en una muestra acotada de artículos. Si bien esto puede ser visto como una debilidad de nuestra revisión, la muestra seleccionada permite a nuestro juicio levantar ciertas inquietudes para orientar futuras investigaciones y sistematizaciones de la literatura en temas de interculturalidad y educación.

Implicancias con relación a los ámbitos de investigación

El hecho de que la investigación en educación intercultural en Chile esté predominantemente focalizada en dos grandes colectivos -indígenas y migrantes-, pues concentra más del noventa por ciento de las investigaciones, evidencia una clara pero preocupante homogeneidad investigativa. Si bien nuestra revisión no ofrece un panorama exhaustivo de las investigaciones en Chile, los análisis demuestran la existencia de una conceptualización restringida y bidimensional del término, que tiende a ignorar otras fuentes de diversidad cultural (Essomba, 2005) como las diferencias de género, las diferencias de clase, las diferencias de orientación sexual o las diferencias confesionales, por citar algunos ejemplos. La presencia anecdótica de una investigación que articula interculturalidad y discapacidad grafica fielmente la uniformidad del corpus de investigaciones. Temas relativos a otras formas de discapacidad, diferencias de género, orientación sexual, diferencias de clase, religión e incluso pertenencia a otras etnias minoritarias no indígenas ${ }^{4}$, en la actualidad están ausentes de la discusión académica en torno a la relación entre interculturalidad y escuela. Son los temas o ámbitos del cual la voz académica no habla, son sus silencios. Algunas de estas lagunas académicas son abordadas habitualmente desde otros marcos conceptuales que guían las investigaciones: así, los temas de discapacidad son abordados desde el movimiento de la inclusión educativa y los actuales proyectos de integración escolar, mientras que los estudios de género son abordados mayoritariamente por investigaciones que se inscriben en marcos postconstruccionistas de movimientos feministas que no necesariamente abordan la relación entre diversidad y escuela.

El análisis con base en el modelo utilizado en nuestra revisión, deja en evidencia que esta homogeneidad investigativa se explica por la predominancia de una conceptualización restringida y reduccionista de entender lo "cultural" en el ámbito educativo. Lejos de una aproximación antropológica del concepto de cultura (Dietz, 2012), más bien hay una comprensión estática y cosificada de lo cultural, que conduce a delimitarlo en aquello que se relaciona con el mundo indígena y con la presencia de inmigrantes; para ambos casos, lo central radica en la existencia de diferencias culturales que se escapan de una supuesta normalidad cultural y que justifica el estudio y alcance de esas diferencias. La principal consecuencia de este encapsulamiento del concepto de cultura radica en opacar su sentido relacional y, por tanto, dinámico en el espacio educativo (Díaz de Rada, 2010). Este encapsulamiento conceptual constituye en sí mismo una

4 El caso de gitanos no escolarizados en Chile, situación ajena a las prioridades de las políticas educativas en Chile en torno a las reformas actuales de mejoramiento de la calidad y equidad del sistema educativo. 
razón suficiente para plantear la necesidad de ampliar la forma en que desde el ámbito académico estamos entendiendo la educación intercultural, y la necesidad por tanto de transitar desde enfoques centrados en el reconocimiento identitario y el fortalecimiento de las relaciones humanas, a enfoques que apuesten por una transformación más amplia de la función social de las escuelas con sus correspondientes prácticas educativas. A nuestro juicio, la necesidad ulterior es la de avanzar hacia una concepción reconstruccionista de la educación intercultural (Sleeter \& Grant, 2009).

\section{Implicancias con relación a los enfoques de investigación}

El hecho de que la investigación en educación intercultural utilice predominantemente dos enfoques de conceptualización de la diversidad refuerza de manera indiscutible la idea de una escasa pluralidad investigativa. Si bien tanto el mantenimiento identitario y el reconocimiento cultural, así como el mejoramiento de las relaciones interpersonales son finalidades educativas insoslayables de todo proyecto educativo intercultural, una interculturalidad comprometida con una educación para la justicia social exige un mayor detenimiento en aspectos vinculados con la lucha contra la desigualdad educativa y, por tanto, la promoción de una educación culturalmente pertinente (Jones \& Vagle, 2013). Aun cuando ocho (8) investigaciones presentan algún grado de vinculación con este enfoque, principios tales como situar las familias y comunidades dentro de un análisis estructural de las inequidades educativas (Chubbuck, 2010; Gorski, 2013), desarrollar relaciones de reciprocidad familia-escuela (Cochran-Smith, 2004), una enseñanza de altas expectativas construidas sobre la cultura, el lenguaje, la experiencia y/o la identidad de los estudiantes (Sleeter, 2009), la creación de un currículum inclusivo que incorpore perspectivas minoritarias y marginalizadas (Ferrada \& Flecha, 2008), así como abordar asuntos que enfrenten explícitamente relaciones de equidad y poder (Jones \& Vagle, 2013), constituyen dimensiones inexploradas o superficialmente abordadas por la investigación académica en materia de educación intercultural. Esto obedece - como hemos visto a lo largo de este trabajo - al hecho de que gran parte de la investigación educativa existente ha privilegiado el estudio de dimensiones educativas específicas que no incorporan necesariamente una discusión mayor en torno a las implicancias políticas de todo proyecto de educación intercultural. En ese sentido, los discursos académicos han privilegiado el uso de enfoques liberales y de "inspiración" crítica centrados en las oportunidades y en las condiciones educativas para acceder a estas oportunidades, pero no necesariamente el uso de enfoques que incorporen la pregunta por las posiciones que los diferentes grupos minoritarios ocupan en el entramado de relaciones que se construyen y legitiman en el espacio educativo.

Amplificar la mirada hacia estos $u$ otros enfoques de educación intercultural que se posicionen desde una perspectiva crítica (Walsh, 2009), constituye un segundo desafío identificado a partir de la sistematización realizada. En el escenario actual, caracterizado por una profunda crisis epistemológica del conocimiento, la investigación en torno a la educación intercultural está llamada a construir más que replicar enfoques existentes (López, 2009, p. 134), para poder desarrollar de esta manera marcos comprensivos renovados y situados que recojan las necesidades y den cuenta de las especificidades de los grupos minoritarios involucrados (Sousa-Santos, 2008).

\section{Implicancias con relación a la función social} de la producción académica

Actualmente, el impacto real de la producción académica en la vida cotidiana de personas e instituciones es materia de cuestionamientos, mientras la transferencia efectiva del conocimiento no siempre tiene lugar en los espacios y momentos adecuados (Fardella \& Sisto, 2015). Sostenemos que la investigación académica debe orientar su quehacer a la producción y difusión de conocimiento socialmente relevante para comprender y transformar el estado actual de nuestra realidad social (Gentili, 2011). En adelante, teniendo en cuenta la agudización de reformas neoliberales que están afectando directamente la reorganización del trabajo académico (Fardella, Sisto \& Jiménez, 2015), se hace necesario recordar con mayor fuerza los efectos performativos de nuestras ciencias sociales (Giddens, 1993) y defender con mayor rigor la necesidad de una investigación educativa orientada a la justicia social (Chubbuck, 2010; Cochran-Smith, 2004; Dover, 2009).

En un escenario de estas características, preguntarse por los enfoques predominantes de educación intercultural utilizados en la producción de conocimientos cobra especial relevancia, en la medida en que - como se ha expuesto a través de esta revisión- prevalece en las narrativas académicas una conceptualización funcionalista y liberal con relación a los propósitos de una educación en contextos de diversidad cultural. En esta línea, de nuestros análisis se desprende la necesidad de que los modelos en educación intercultural no giren únicamente en la órbita del mantenimiento cultural y de celebración de las diferencias, que no solo estén orientados al trabajo en escuelas con presencia de estudiantes de grupos étnico-culturales minoritarios, sino que apuesten por un proyecto político que permita reconstruir socialmente el sentido y la experiencia educativa de todos sus participantes (Sleeter \& Grant, 2009). 


\section{Sobre los autores}

Felipe Jiménez-Vargas es doctor en Psicología de la Educación por la Universidad Autónoma de Barcelona, UAB, España. Ha investigado en los últimos años la relación entre migración y escuela, y se ha centrado en los modelos de gestión de la diversidad, las prácticas educativas $\mathrm{y}$, actualmente, los programas de acogida al sistema educativo.

Carmen Montecinos-Sanhueza es PhD en Psicología Educacional, Southern Illinois University-Carbondale, Estados Unidos. Profesora titular de la Escuela de Psicología de la Pontificia Universidad Católica de Valparaíso, Chile y directora ejecutiva del Centro de Liderazgo para la Mejora Escolar. Ha realizado investigación en temas de formación inicial y continua de profesores, mejora escolar y aprendizaje situado de directores noveles.

\section{Referencias}

Almendra-Soto, O.; Peña-Cortés, F. \& Rojas-Maturana, M. (2011). Relación entre saberes y conocimientos territoriales en escuelas lafkenches: la necesidad de un currículum intercultural con base geográfica. Revista de Estudios y Experiencias en Educación, 10 (20), 35-58. Disponible en: http://www.rexe.cl/ojournal/index.php/rexe/article/view/109/116

Banks, J. A. (2004). Teaching for Social Justice, Diversity, and Citizenship in a Global World. The Educational Forum, 68 (4), 289-298. Disponible en: http://depts.washington.edu/centerme/Fs04banks.pdf

Barandica i Pairet, E. (1999). Educación y multiculturalidad. Análisis, modelos y ejemplos de experiencias escolares. En M. Essomba \& E. Barandica i Pairet (coords.). Construir la escuela intercultural: reflexiones y propuestas para trabajar la diversidad étnica y cultural, 15-20. Barcelona: Graó.

Becerra, S. \& Flores, V. (2011). Prejuicio étnico y desgaste docente: un desafío en contextos de pobreza. Revista Electrónica Diálogos Educativos, 10 (20), 15-40. Disponible en: https://dialnet.unirioja.es/descarga/ articulo/3728298.pdf

Bronfenbrenner, U. (1987). La ecología del desarrollo humano. Barcelona: Paidós.

Carrasco-Gutiérrez, A. \& Gavilán-Vega, V. (2012). Influencia del proceso de enseñanza escolar fiscal en la socialización de mujeres y hombres aymara de la zona altiplánica del norte de Chile. Estudios Atacameños, 44, 73-88. https://scielo.conicyt.cl/pdf/eatacam/n44/art04.pdf

Catalán, R. (2013). Prácticas y discursos pedagógicos en Toconao. Cultura, patrimonio e interculturalidad. Estudios Atacameños, 45, 19-40. Disponible en: https://scielo.conicyt.cl/pdf/eatacam/n45/art03.pdf

Chile, Ministerio de Educación (2002). Aspectos generales de la Educación Intercultural Bilingüe (EIB) y sus Fundamentos. Santiago de Chile: Ministerio de Educación.

Chile, Ministerio de Educación (2016). Orientaciones para la construcción de comunidades educativas inclusivas. División de Educación General. Coordinación Nacional de Inclusión y Diversidad. Disponible en: https://www.mineduc.cl/wp-content/uploads/sites/19/2017/03/ Documento-Orientaciones-28.12.16.pdf

Chile, Ministerio de Educación (2017). Orientaciones técnicas para la inclusión educativa de estudiantes extranjeros. División de Educación General. Coordinación Nacional de Inclusión y Diversidad. Disponible en: https://www.ayudamineduc.cl/sites/default/files/orientacionesestudiantes-extranjeros-21-12-17.pdf 
Chile, Ministerio de Educación (2018). Política nacional de estudiantes extranjeros 2018-2022. Santiago de Chile: Ministerio de Educación, Gobierno de Chile. Disponible en: https://migrantes.mineduc.cl/ wp-content/uploads/sites/88/2018/06/POLITICA-NACIONAL-EE-Fi nal-1-1.pdf

Chubbuck, S. (2010). Individual and Structural Orientations in Socially Just Teaching: Conceptualization, Implementation, and Collaborative Effort. Journal of Teacher Education, 61 (3), 197-210. https://doi. org/10.1177/0022487109359777

Cochran-Smith, M. (2004). Walking the Road: Race, Diversity and Social Justice in Teacher Education. New York: Teachers College Press.

Díaz de Rada, Á. (2010). Cultura, antropología y otras tonterías. Madrid: Trotta.

Dietz, G. (2012). Multiculturalismo, interculturalismo y diversidad en educación. Una aproximación antropológica. Ciudad de México: Fondo de Cultura Económica, FCE.

Dietz, G. \& Mateos, L. (2013). Interculturalidad y educación intercultural en México. Un análisis de los discursos nacionales e internacionales en su impacto en los modelos educativos mexicanos. Ciudad de México: Secretaría de Educación Pública, SEP. Disponible en: https://eib.sep. gob.mx/isbn/9786079116040.pdf

Dijk, T. van (2009). Discurso y poder. Barcelona: Gedisa.

Dover, A. (2009). Teaching for Social Justice and K-12 Student Outcomes: A Conceptual Framework and Research Review. Equity and Excellence in Education, 42 (4), 506-524.

Essomba, M. A. (2005). L'atenció a la diversitat a Catalunya: debat en el sistema educatiu. Vic: Eumo.

Essomba, M. A. (2006). Liderar escuelas interculturales e inclusivas. Equipos directivos y profesorado ante la diversidad cultural y la inmigración. Barcelona: Graó.

Fardella, C. (2013a). La neoliberalización de la profesión docente en Chile. Adscripción, creación y cambio. Tesis doctoral. Universidad Autónoma de Barcelona, Barcelona. Disponible en: https://www.tdx.cat/ bitstream/handle/10803/125866/cfc1de1. pdf; sequence $=1$

Fardella, C. (2013b). Resistencias cotidianas en torno a la institucionalización del modelo neoliberal en las políticas educacionales: el caso de la docencia en Chile. Psicoperspectivas, 12 (2), 83-92. Disponible en: http://www.psicoperspectivas.cl/index.php/psicoperspectivas/arti cle/viewFile/294/285

Fardella, C. \& Sisto, V. (2015). La reorganización del trabajo académico y la propuesta de un nuevo enfoque para su estudio: identidad laboral y práctica cotidiana. En S. Lago Martínez \& N. Correa (eds.). Desafíos y dilemas de la universidad y la ciencia en América Latina y el Caribe en el siglo XXI, 83-92. Buenos Aires: Editorial Teseo. Disponible en: http://esic.sociales.uba.ar/media/Desaf\%C3\%ADos\%20y\%20dile mas\%20de\%20la\%20Universidad.pdf

Fardella, C.; Sisto, V. \& Jiménez, F. (2015). Nosotros los académicos. Narrativas identitarias y autodefinición en la universidad actual. Universitas Psychologica, 14 (5), 1625-1636. DOI: https://doi.org/10.11144/ Javeriana.upsy14-5.nani. Disponible en: http://revistas.javeriana.edu. co/index.php/revPsycho/article/view/10715

Ferrada, D. \& Flecha, R. (2008). El modelo dialógico de la pedagogía: un aporte desde las experiencias de comunidades de aprendizaje. Estudios Pedagógicos, 34 (1), 41-61. Disponible en: https://scielo.conicyt. cl/pdf/estped/v34n1/art03.pdf 
Ferrão, V. (2010). Educación intercultural en América Latina: distintas concepciones y tensiones actuales. Estudios Pedagógicos, 36 (2), 333342. http://dx.doi.org/10.4067/S0718-07052010000200019. Disponible en: https://scielo.conicyt.cl/pdf/estped/v36n2/art19.pdf

Flick, U. (2009). An Introduction to Qualitative Research. Thousand Oaks, California: SAGE Publications.

Forno, A.; Álvarez-Santullano, P. \& Rivera, R. (2009). Entre el edificio y el currículum de la interculturalidad: una mirada antropológica a la educación actual en territorio mapuche-huilliche. Chungará, Revista de Antropología Chilena, 41 (2), 287-298. Disponible en: https://scielo. conicyt.cl/pdf/chungara/v41n2/art09.pdf

Gentili, P. (2011). Pedagogía de la igualdad. Ensayos contra la educación excluyente. Buenos Aires: Siglo XXI. Disponible en: http://radiopro gresohn.cedoh.org/Biblioteca_CEDOH/archivos/0094\%20PEDA GOGIA\%20DE\%20LA\%20IGUALDAD\%20ENSAYOS\%20SOBRE\%20 LA\%20EDUCACION\%20EXCLUYENTE.pdf

Giddens, A. (1993). Las nuevas reglas del método sociológico. Buenos Aires: Amorrortu. Disponible en: https://sociologiaycultura.files.word press.com/2014/02/giddens-anthony-las-nuevas-reglas-del-metodosociologico.pdf

Giménez-Romero, C. (2003). Pluralismo, multiculturalismo e interculturalidad. Propuestas de clarificación y apuntes educativos. Educación y Futuro: Revista de Investigación Aplicada y Experiencias Educativas, 8, 9-26. Disponible en: https://dialnet.unirioja.es/ejemplar/138249

Giménez-Romero, C. (2009). Interculturalisme. Definició, especificitat i dimensions. Barcelona Societat. Revista de Coneixement i Anàlisi Social, 16, 32-41. Disponible en: http://ajuntament.barcelona.cat/dret ssocials/sites/default/files/revista/revista16-art1-interculturalisme.pdf

Glaser, B. \& Strauss, A. (1967). Discovery of Grounded Theory: Strategies for Qualitative Research. Chicago: Aldine.

Gorski, P. (2006). Complicity with Conservatism: The De-Politicizing of Multicultural and Intercultural Education. Intercultural Education, 17 (2), 163-177. Disponible en: http://www.edchange.org/publications/ Complicity_with_Conservatism.pdf

Gorski, P. (2009). What We're Teaching Teachers: An Analysis of Multicultural Teacher Education Coursework Syllabi. Teaching and Teacher Education, 25, 309-318. Disponible en: http://www.academia. edu/389656/What_Were_Teaching_Teachers_An_Analysis_of_Mul ticultural_Teacher_Education_Courses

Gorski, P. (2013). Reaching and Teaching Students in Poverty: Strategies for Erasing the Opportunity Gap. New York: Teachers College Press.

Grant, M. \& Booth, A. (2009). A Typology of Reviews: An Analysis of 14 Types and Associated Methodologies. Health Information \& Libraries Journal, 26, 91-108. DOI: 10.1111/j.1471-1842.2009.00848.x

Grant, C. \& Sleeter, C. (2006). Turning on Learning: Five Approaches to Multicultural Teaching Plans for Race, Class, Gender and Disability. Upper Saddle River, New Jersey: Prentice-Hall.

Hein, K. (2012). Migración y transición: hijos de inmigrantes de origen latinoamericano en su transición de la escuela al trabajo en Chile. Si Somos Americanos. Revista de Estudios Transfronterizos, 12 (1), 101126. Disponible en: http://www.sisomosamericanos.cl/index.php/ sisomosamericanos/article/view/72/77

Ibáñez, N. (2010). El contexto interaccional y la diversidad en la escuela. Estudios Pedagógicos, 36 (1), 275-286. Disponible en: http://mingaon line.uach.cl/pdf/estped/v36n1/art15.pdf 
Jenks, C.; Lee, J. \& Kanpol, B. (2001). Approaches to Multicultural Education in Preservice Teacher Education: Philosophical Frameworks and Models for Teaching. The Urban Review, 33 (2), 87-105. DOI: 10.1023/A:1010389023211

Jiménez, F. (2012). Violencia escolar en contextos educativos multiculturales: una aproximación desde los modelos de gestión de la diversidad cultural. Psicoperspectivas, 11 (2), 12-34. Disponible en: http:// www.psicoperspectivas.cl/index.php/psicoperspectivas/article/ view/205/232

Jiménez, F. \& Fardella, C. (2015). Diversidad y rol de la escuela: discursos del profesorado en contextos educativos multiculturales en clave migratoria. Revista Mexicana de Investigación Educativa, RMIE, 20 (65), 419-441. Disponible en: http://www.scielo.org.mx/pdf/rmie/ v20n65/v20n65a5.pdf

Jones, S. \& Vagle, M. D. (2013). Living Contradictions and Working for Change: Toward a Theory of Class-Sensitive Pedagogy. Educational Researcher, 42 (3), 129-141. https://doi.org/10.3102/0013189X13481381

Lalueza, J. L. (2012). Modelos psicológicos para la explicación de la diversidad cultural. Cultura y Educación, 24 (2), 149-162. DOI: 10.1174/11356401 2804932119

López, L. E. (2009). Interculturalidad, educación y ciudadanía. Perspectivas latinoamericanas. La Paz: Plural Editores.

Marfán, J.; Castillo, P.; González, R. \& Ferreira, I. (2013). Informe final de estudio: análisis de la implementación de los Programas de Integración Escolar (PIE) en establecimientos que han incorporado estudiantes con Necesidades Educativas Especiales Transitorias (NEET). Santiago: Centro de Innovación en Educación, CIE. Disponible en: https://especial. mineduc.cl/documentacion/estudios-y-documentos/

Mato, D. (2005). Interculturalidad, producción de conocimientos y prácticas socioeducativas. Alceu, 6 (11), 120-138. Disponible en: http:// revistaalceu.com.puc-rio.br/media/Alceu_n11_Mato.pdf

Montecinos, C. (2004). Analizando la política de educación intercultural bilingüe en Chile desde la educación multicultural y reconstructivista. Cuadernos Interculturales, 2 (3), 25-32. Disponible en: https://www.psiucv.cl/wp-content/uploads/2012/11/Analizando-lapol\%C3\%ADtica-de.pdf

Montecinos, C. (2011). Propuestas para una educación que es multicultural. En G. Williamson \& C. Montecinos (orgs.). Educación multicultural. Práctica de la equidad y diversidad para un mundo que demanda esperanza, 15-42. Talca: Ediciones Universidad de la Frontera. Disponible en: http://humanidades.ufro.cl/images/libros/libro-EDUCA CION-MULTICULTURAL.pdf

Montecinos, C. \& Ríos, F. (1999). Assessing Preservice Teachers' Zones of Concern and Comfort with Multicultural Education. Teacher Education Quarterly, 26, 7-24. Disponible en: https://www.psiucv.cl/wpcontent/uploads/2012/11/Assessing-Preservice-Teachers.pdf

Navas-Martínez, L.; Holgado-Tello, F. P. \& Sánchez-Bravo, A. (2009). Predicción de los estereotipos académicos ante los estudiantes inmigrantes. Horizontes Educacionales, 14 (2), 37-47. Disponible en: http://www. redalyc.org/pdf/979/97915161004.pdf

Navas-Martínez, L. \& Sánchez-Bravo, A. (2010). Actitudes de los estudiantes de pedagogía de las regiones del Bío Bío y la Araucanía de Chile hacia la presencia de niños inmigrantes en la escuela: análisis diferenciales. Psykhe, 19 (1), 47-60. Disponible en: https://scielo.conicyt. cl/pdf/psykhe/v19n1/art04.pdf 
Olate, A. \& Henríquez B., M. (2010). Actitudes lingüísticas de profesores mapuche de educación básica: vigencia y enseñanza del mapudungun en el contexto educativo. Literatura y Lingüística, 22, 103-116. Disponible en: http://www.redalyc.org/pdf/352/35218817008.pdf

Paz, M. V. de la \& Salamanca-Salucci, M. (2009). Elementos de la cultura sorda: una base para el currículum intercultural. Revista de Estudios y Experiencias en Educación, REXE, 8 (15), 31-49. Disponible en: http:// www.redalyc.org/articulo.oa?id $=243116377002$

Peña-Sandoval, C. (2015). La pedagogía culturalmente relevante y sus posibilidades en el contexto chileno. Revista Vínculos, 2 (2), 73-100. Disponible en: http://revistavinculos.blogspot.com/2016/03/normal0-21-false-false-false-es-cl-x_51.html

Pidgeon, N. \& Henwood, K. (1997). Grounded Theory: Practical Implementation. En J. Richardson (comp.). Handbook of Qualitative Research Methods for Psychology and the Social Sciences, 86-101. Leicester: BPS Books.

Quidel-Calitraf, G. (2011). Estrategias de enseñanza de la lengua mapunzugun en el marco del PEIB Mineduc-Orígenes (Comuna de Padre de Las Casas, IX Región, Chile). Cuadernos Interculturales, 9 (16), 61-80. Disponible en: http://www.redalyc.org/pdf/552/55218731005.pdf

Quilaqueo-Rapimán, D. (2006). Valores educativos mapuches para la formación de persona desde el discurso de kimches. Estudios Pedagógicos, 32 (2), 73-86. Disponible en: http://www.redalyc.org/articulo. oa? id =173514131003

Quilaqueo-Rapimán, D. (2012). Saberes educativos mapuches: racionalidad apoyada en la memoria social de los kimches. Atenea, 505, 79-102. Disponible en: https://scielo.conicyt.cl/pdf/atenea/n505/art_04.pdf

Quilaqueo-Rapimán, D. \& Quintriqueo, S. (2007). Conocimientos educativos vernáculos para la innovación curricular en contexto mapuche. Revista de Psicología de la Universidad de Chile, 16 (1), 97-121. DOI: 10.5354/0719-0581.2012.18428. Disponible en: https://revistapsico logia.uchile.cl/index.php/RDP/article/view/18428/19463

Quilaqueo-Rapimán, D. \& Quintriqueo, S. (2008). Formación docente en educación intercultural para contexto mapuche en Chile. Cuadernos Interculturales, 6 (10), 91-110. Disponible en: http://www.redalyc.org/ pdf/552/55261006.pdf

Quilaqueo-Rapimán, D. \& Quintriqueo, S. (2010). Saberes educativos mapuches: un análisis desde la perspectiva de los kimches. Polis, Revista Latinoamericana, 9 (26), 337-360. Disponible en: http://www. redalyc.org/articulo.oa?id $=30515373016$

Quilaqueo-Rapimán, D. \& San Martín, D. (2008). Categorización de saberes educativos mapuche mediante la teoría fundamentada. Estudios Pedagógicos, 34 (2), 151-168. Disponible en: https://scielo.conicyt.cl/ pdf/estped/v34n2/art09.pdf

Quilaqueo-Rapimán, D.; Quintriqueo, S. \& San Martín, D. (2011). Contenido de aprendizajes educativos mapuches para el marco conceptual de un currículum escolar intercultural. Estudios Pedagógicos, 37 (2), 233-248. Disponible en: https://scielo.conicyt.cl/pdf/estped/v37n2/ art14.pdf

Quintriqueo, S. \& Maheux, G. (2004). Exploración del conocimiento sobre la relación de parentesco como contenido educativo para un currículum escolar intercultural en comunidades mapunche. Revista de Psicología de la Universidad de Chile, 13 (1), 73-91. Disponible en: https:// revistapsicologia.uchile.cl/index.php/RDP/article/view/17488/18259 
Quintriqueo, S. \& McGinity, M. (2009). Implicancias de un modelo curricular monocultural en la construcción de la identidad sociocultural de alumnos/as mapuches de la IX región de la Araucanía, Chile. Estudios Pedagógicos, 35 (2), 173-188. Disponible en: http://www.redalyc. org/articulo.oa?id=173514137010

Quintriqueo, S. \& Torres, H. (2013). Construcción de conocimiento mapuche y su relación con el conocimiento escolar. Estudios Pedagógicos, 39 (1), 199-216. Disponible en: https://scielo.conicyt.cl/pdf/estped/ v39n1/art12.pdf

Riedemann, A. (2008). La educación intercultural bilingüe en Chile. ¿Ampliación de oportunidades para alumnos indígenas? Indiana, 25, 169-193. Disponible en: https://www.iai.spk-berlin.de/fileadmin/do kumentenbibliothek/Indiana/Indiana_25/Indiana_25_169-193_Rie demann.pdf

Riedemann, A. \& Stefoni, C. (2015). Sobre el racismo, su negación, y las consecuencias para una educación anti-racista en la enseñanza secundaria chilena. Polis, Revista Latinoamericana, 42, 191-216. Disponible en: https://journals.openedition.org/polis/11327

Romero-Medina, A. (2010). Educación por y para indígenas y afrocolombianos: las tecnologías de la etnoeducación. Magis, Revista Internacional de Investigación en Educación, 3 (5), 167-182. Disponible en: http:// revistas.javeriana.edu.co/index.php/MAGIS/article/view/3534

Rother, T. (2005). Conflicto intercultural y educación en Chile: desafíos y problemas de la educación intercultural bilingüe (EIB) para el pueblo mapuche. Revista Austral de Ciencias Sociales, 9, 71-84. Disponible en: http://mingaonline.uach.cl/pdf/racs/n9/art07.pdf

Sánchez-Bravo, A.; Navas-Martínez, L. \& Holgado-Tello, P. (2013). Inmigración y educación intercultural en la formación inicial docente. Estudios Pedagógicos, 39 (1), 239-251. Disponible en: https://scielo. conicyt.cl/pdf/estped/v39n1/art14.pdf

Silva-Peña, I.; Bastidas, K.; Calfuqueo, L.; Díaz, J. \& Valenzuela, J. (2013). Sentido de la Escuela para niños y niñas mapuche en una zona rural. Polis, Revista Latinoamericana, 12(34), 243-258. Disponible en: https://journals.openedition.org/polis/8856?lang=es

Sleeter, C. (2009). Teacher Education, Neoliberalism, and Social Justice. In W. Ayers, T. Quinn \& D. Stovall (eds.). The Handbook of Social Justice in Education, 611-624. New York: Routledge.

Sleeter, C. (2013). Teaching for Social Justice in Multicultural Classroom. Multicultural Education Review, 5 (2), 1-18. DOI: 10.14328/ MER.2013.09.30.01

Sleeter, C. \& Grant, C. (2009). Making Choices for Multicultural Education: Five Approaches to Race, Class and Gender. $6^{\text {th }}$ ed. New York: Wiley.

Sleeter, C.; Montecinos, C. \& Jiménez, F. (2016). Preparing Teachers for Social Justice in the Context of Education Policies that Deepen Class Segregation in Schools: The Case of Chile. En G. Noblit \& W. Pink (eds.). Teacher Education for High Poverty Schools, 171-191. New York: Springer Series.

Sousa-Santos, B. de (2008). Conocer desde el sur: para una cultura política emancipatoria. La Paz: Plural Editores. Disponible en: http://www. boaventuradesousasantos.pt/media/Conocer\%20desde\%20el\%20 Sur_Lima_2006.pdf

Tijoux, M. E. (2013). Las escuelas de la inmigración en la ciudad de Santiago: elementos para una educación contra el racismo. Polis, Revista Latinoamericana, 12 (35), 287-307. Disponible en: https://scielo.conicyt. cl/pdf/polis/v12n35/art13.pdf 
Tubino, F. (2005). La interculturalidad crítica como proyecto ético-político. Encuentro Continental de Educadores Agustinos, Lima, 24-28 de enero de 2005. Disponible en: http://oala.villanova.edu/congresos/ educación/lima-ponen-02.html

Walsh, C. (2005). Interculturalidad, colonialidad y educación. Ponencia presentada en el Primer Seminario Internacional "(Etno) educación, multiculturalismo e interculturalidad", Bogotá, 1-4 de noviembre de 2005. Disponible en: http://www.flacsoandes.edu.ec/sites/default/fi les/agora/files/1265909654.interculturalidad__colonialidad_y_edu cacion_0.pdf

Walsh, C. (2009). Interculturalidad, Estado, Sociedad: Iuchas (de)coloniales de nuestra época. Quito: Universidad Andina Simón Bolívar, Abya Yala. Disponible en: http://clar.org/assets/interculturalidadestadoso ciedad.pdf

Williamson, G. (2011). Educación multicultural para una pedagogía de la pluralidad. En G. Williamson \& C. Montecinos (orgs.). Educación multicultural: práctica de la equidad y diversidad para un mundo que demanda esperanza, 73-109. Temuco, Chile: Ediciones Universidad de la Frontera. Disponible en: http://humanidades.ufro.cl/images/libros/ libro-EDUCACION-MULTICULTURAL.pdf

Williamson, G. \& Montecinos, C. (2001). Addressing Equity and Social Justice Concerns in Chile's Formal and Informal Education: An Historical and Contemporary Analysis. In C. A. Grant \& J. Lei (eds.). Global Constructions of Multicultural Education: Theories and Realities, 355378. Mahwah, New Jersey: Lawrence Erlbaum Associates.

Williamson, G.; Pérez, I.; Collia, G.; Modesto, F. \& Raín, N. (2012). Docentes rurales, infancia y adolescencia mapuche. Psicoperspectivas, 11 (2), 77-96. Disponible en: https://scielo.conicyt.cl/pdf/psicop/v11n2/ art05.pdf

Zapata, R. (2011). Formación del futuro profesorado en diversidad cultural: estudio de un caso en el contexto universitario chileno. Akadèmeia, 2 (2).

Zeichner, K. (2010). La formación del profesorado y la lucha por la justicia social. Madrid: Morata. 
Anexo 1

Caracterización de artículos analizados

\begin{tabular}{|c|c|c|c|c|c|}
\hline Título & Autor (es) & Revista & $\begin{array}{l}\text { Año de } \\
\text { publicación }\end{array}$ & Ámbito & $\begin{array}{l}\text { Foco/Tema/ } \\
\text { Ámbito }\end{array}$ \\
\hline $\begin{array}{l}\text { Exploración del conocimiento } \\
\text { sobre la relación de } \\
\text { parentesco como contenido } \\
\text { educativo para un currículum } \\
\text { escolar intercultural en } \\
\text { comunidades mapunche }\end{array}$ & $\begin{array}{l}\text { Segundo } \\
\text { Quintriqueo M. \& } \\
\text { Gisèle Maheux }\end{array}$ & $\begin{array}{l}\text { Revista de } \\
\text { Psicología }\end{array}$ & 2004 & Etnias & $\begin{array}{l}\text { Sistematización } \\
\text { de conocimientos } \\
\text { indígenas }\end{array}$ \\
\hline $\begin{array}{l}\text { Conflicto intercultural y } \\
\text { educación en Chile: desafíos } \\
\text { y problemas de la educación } \\
\text { intercultural bilingüe (EIB) } \\
\text { para el pueblo mapuche }\end{array}$ & Tanja Rother & $\begin{array}{l}\text { Revista Austral } \\
\text { de Ciencias } \\
\text { Sociales }\end{array}$ & 2005 & Etnias & $\begin{array}{l}\text { Percepción de } \\
\text { actores educativos } \\
\text { del Programa } \\
\text { de Educación } \\
\text { Intercultural } \\
\text { Bilingüe, PEIB }\end{array}$ \\
\hline $\begin{array}{l}\text { Valores educativos mapuches } \\
\text { para la formación de } \\
\text { persona desde el discurso } \\
\text { de kimches }\end{array}$ & $\begin{array}{l}\text { Daniel Quilaqueo } \\
\text { Rapimán }\end{array}$ & $\begin{array}{l}\text { Estudios } \\
\text { Pedagógicos }\end{array}$ & 2006 & Etnias & $\begin{array}{l}\text { Análisis de valores } \\
\text { educativos } \\
\text { mapuches }\end{array}$ \\
\hline $\begin{array}{l}\text { Conocimientos educativos } \\
\text { vernáculos para la innovación } \\
\text { curricular en contexto } \\
\text { mapuche }\end{array}$ & $\begin{array}{l}\text { Daniel Quilaqueo } \\
\& \text { Segundo } \\
\text { Quintriqueo }\end{array}$ & $\begin{array}{l}\text { Revista de } \\
\text { Psicología }\end{array}$ & 2007 & Etnias & $\begin{array}{l}\text { Sistematización de } \\
\text { saberes indígenas }\end{array}$ \\
\hline $\begin{array}{l}\text { Categorización de saberes } \\
\text { educativos mapuche mediante } \\
\text { la teoría fundamentada }\end{array}$ & $\begin{array}{l}\text { Daniel Quilaqueo } \\
\text { Rapimán \& Daniel } \\
\text { San Martín }\end{array}$ & $\begin{array}{l}\text { Estudios } \\
\text { Pedagógicos }\end{array}$ & 2008 & Etnias & $\begin{array}{l}\text { Sistematización de } \\
\text { saberes indígenas }\end{array}$ \\
\hline $\begin{array}{l}\text { Formación docente en } \\
\text { educación intercultural para } \\
\text { contexto mapuche en Chile }\end{array}$ & $\begin{array}{l}\text { Daniel Quilaqueo } \\
\& \text { Segundo } \\
\text { Quintriqueo }\end{array}$ & $\begin{array}{l}\text { Cuadernos } \\
\text { Interculturales }\end{array}$ & 2008 & Etnias & $\begin{array}{l}\text { Valoración (logros } \\
\text { y desafíos) de la } \\
\text { formación inicial } \\
\text { docente intercultural }\end{array}$ \\
\hline $\begin{array}{l}\text { Elementos de la cultura sorda. } \\
\text { Una base para el currículum } \\
\text { intercultural }\end{array}$ & $\begin{array}{l}\text { María Victoria } \\
\text { de la Paz } \\
\& \text { Marcelo } \\
\text { Salamanca } \\
\text { Salucci }\end{array}$ & $\begin{array}{l}\text { Revista de } \\
\text { Estudios y } \\
\text { Experiencias en } \\
\text { Educación, REXE }\end{array}$ & 2009 & $\begin{array}{l}\text { Cultura } \\
\text { sorda }\end{array}$ & $\begin{array}{l}\text { Sistematización de } \\
\text { elementos culturales }\end{array}$ \\
\hline $\begin{array}{l}\text { Implicancias de un modelo } \\
\text { curricular monocultural en la } \\
\text { construcción de la identidad } \\
\text { sociocutural de alumnos/as } \\
\text { mapuches de la IX región de } \\
\text { la Araucanía, Chile }\end{array}$ & $\begin{array}{l}\text { Segundo } \\
\text { Quintriqueo } \\
\text { Millán \& } \\
\text { Margaret } \\
\text { McGinity Travers }\end{array}$ & $\begin{array}{l}\text { Estudios } \\
\text { Pedagógicos }\end{array}$ & 2009 & Etnias & $\begin{array}{l}\text { Percepciones } \\
\text { de los actores } \\
\text { educativos respecto } \\
\text { a los contenidos } \\
\text { curriculares }\end{array}$ \\
\hline $\begin{array}{l}\text { Entre el edificio y el currículum } \\
\text { de la interculturalidad. Una } \\
\text { mirada antropológica a la } \\
\text { educación actual en territorio } \\
\text { mapuche-huilliche }\end{array}$ & $\begin{array}{l}\text { Amilcar Forno, } \\
\text { Pilar Álvarez } \\
\text { Santullano \& } \\
\text { Rita Rivera }\end{array}$ & Chungará & 2009 & Etnias & $\begin{array}{l}\text { Efectos de la } \\
\text { implementación } \\
\text { de la Educación } \\
\text { Intercultural } \\
\text { Bilingüe, EIB }\end{array}$ \\
\hline $\begin{array}{l}\text { Predicción de los estereotipos } \\
\text { académicos ante los } \\
\text { estudiantes inmigrantes }\end{array}$ & $\begin{array}{l}\text { Leandro Navas } \\
\text { Martínez, } \\
\text { Francisco Pablo } \\
\text { Holgado Tello } \\
\text { \& Alejandra } \\
\text { Sánchez Bravo }\end{array}$ & $\begin{array}{l}\text { Horizontes } \\
\text { Educacionales }\end{array}$ & 2009 & Inmigración & $\begin{array}{l}\text { Actitudes ante } \\
\text { la inmigración } \\
\text { y educación } \\
\text { intercultural }\end{array}$ \\
\hline $\begin{array}{l}\text { Saberes educativos mapuches. } \\
\text { Un análisis desde la } \\
\text { perspectiva de los kimches }\end{array}$ & $\begin{array}{l}\text { Daniel Quilaqueo } \\
\text { Rapimán \& } \\
\text { Segundo } \\
\text { Quintriqueo }\end{array}$ & $\begin{array}{l}\text { Polis, Revista } \\
\text { Latinoamericana }\end{array}$ & 2010 & Etnias & $\begin{array}{l}\text { Sistematización de } \\
\text { saberes indígenas }\end{array}$ \\
\hline
\end{tabular}




\begin{tabular}{|c|c|c|c|c|c|}
\hline Título & Autor (es) & Revista & $\begin{array}{l}\text { Año de } \\
\text { publicación }\end{array}$ & Ámbito & $\begin{array}{l}\text { Foco/Tema/ } \\
\text { Ámbito }\end{array}$ \\
\hline $\begin{array}{l}\text { El contexto interaccional y la } \\
\text { diversidad en la escuela }\end{array}$ & Nolfa Ibáñez & $\begin{array}{l}\text { Estudios } \\
\text { Pedagógicos }\end{array}$ & 2010 & Etnias & $\begin{array}{l}\text { Actitudes hacia } \\
\text { las experiencias } \\
\text { y conocimientos } \\
\text { previos }\end{array}$ \\
\hline $\begin{array}{l}\text { Actitudes lingüísticas de } \\
\text { profesores mapuche de } \\
\text { educación básica. Vigencia y } \\
\text { enseñanza del mapudungun } \\
\text { en el contexto educativo }\end{array}$ & $\begin{array}{l}\text { Aldo Olate } \\
\text { V. \& Marisol } \\
\text { Henríquez B. }\end{array}$ & $\begin{array}{l}\text { Literatura y } \\
\text { Lingüística }\end{array}$ & 2010 & Etnias & $\begin{array}{l}\text { Actitudes } \\
\text { lingüísticas y } \\
\text { actitudes hacia } \\
\text { el Programa } \\
\text { de Educación } \\
\text { Intercultural } \\
\text { Bilingüe, PEIB }\end{array}$ \\
\hline $\begin{array}{l}\text { Actitudes de los estudiantes } \\
\text { de pedagogía de las regiones } \\
\text { del Bío Bío y la Araucanía de } \\
\text { Chile hacia la presencia de } \\
\text { niños inmigrantes }\end{array}$ & $\begin{array}{l}\text { Leandro Navas } \\
\text { Martínez \& } \\
\text { Alejandra } \\
\text { Sánchez Bravo }\end{array}$ & Psykhe & 2010 & Inmigración & $\begin{array}{l}\text { Actitudes hacia } \\
\text { la educación } \\
\text { multicultural }\end{array}$ \\
\hline $\begin{array}{l}\text { Formación del futuro } \\
\text { profesorado en diversidad } \\
\text { cultural. Estudio de un } \\
\text { caso en el contexto } \\
\text { universitario chileno }\end{array}$ & Rosa Zapata & Akadèmeia & 2011 & $\begin{array}{l}\text { Diversidad } \\
\text { cultural } \\
\text { (etnias) }\end{array}$ & $\begin{array}{l}\text { Creencias de } \\
\text { profesores } \\
\text { (formadores y } \\
\text { egresados) respecto } \\
\text { a la diversidad } \\
\text { cultural, educación } \\
\text { multicultural y } \\
\text { formación docente } \\
\text { en diversidad }\end{array}$ \\
\hline $\begin{array}{l}\text { Relación entre saberes } \\
\text { y conocimientos territoriales } \\
\text { en escuelas lafkenches: } \\
\text { la necesidad de un } \\
\text { currículum intercultural } \\
\text { con base geográfica }\end{array}$ & $\begin{array}{l}\text { Osvaldo } \\
\text { Almendra Soto, } \\
\text { Fernando Peña } \\
\text { Cortés \& Marcela } \\
\text { Rojas Maturana }\end{array}$ & $\begin{array}{l}\text { Revista de } \\
\text { Estudios y } \\
\text { Experiencias en } \\
\text { Educación, REXE }\end{array}$ & 2011 & Etnias & $\begin{array}{l}\text { Presencia/ausencia } \\
\text { saberes territoriales } \\
\text { mapuches en el } \\
\text { currículo escolar }\end{array}$ \\
\hline $\begin{array}{l}\text { Contenido de aprendizajes } \\
\text { educativos mapuches } \\
\text { para el marco conceptual } \\
\text { de un currículum escolar } \\
\text { intercultural }\end{array}$ & \begin{tabular}{|l|} 
Daniel Quilaqueo \\
Rapimán, \\
Segundo \\
Quintriqueo \& \\
Daniel San Martín
\end{tabular} & $\begin{array}{l}\text { Estudios } \\
\text { Pedagógicos }\end{array}$ & 2011 & Etnias & $\begin{array}{l}\text { Sistematización de } \\
\text { saberes indígenas }\end{array}$ \\
\hline $\begin{array}{l}\text { Estrategias de enseñanza } \\
\text { de la lengua mapunzugun } \\
\text { en el marco del PEIB } \\
\text { Mineduc-Orígenes }\end{array}$ & $\begin{array}{l}\text { Gloria Quidel } \\
\text { Calitraf }\end{array}$ & $\begin{array}{l}\text { Cuadernos } \\
\text { Interculturales }\end{array}$ & 2011 & Etnias & $\begin{array}{l}\text { Sistematización } \\
\text { de estrategias } \\
\text { metodológicas en } \\
\text { la enseñanza de la } \\
\text { lengua }\end{array}$ \\
\hline $\begin{array}{l}\text { Prejuicio étnico y desgaste } \\
\text { docente. Un desafío en } \\
\text { contextos de pobreza }\end{array}$ & $\begin{array}{l}\text { Sandra Becerra } \\
\text { Peña \& Víctor } \\
\text { Flores Cantero }\end{array}$ & $\begin{array}{l}\text { Diálogos } \\
\text { Educativos }\end{array}$ & 2011 & Etnias & $\begin{array}{l}\text { Creencias en torno a } \\
\text { alumnado mapuche, } \\
\text { prejuicio étnico y } \\
\text { desgaste profesional } \\
\text { docente }\end{array}$ \\
\hline $\begin{array}{l}\text { Saberes educativos mapuches. } \\
\text { Racionalidad apoyada en la } \\
\text { memoria social de los kimches }\end{array}$ & $\begin{array}{l}\text { Daniel Quilaqueo } \\
\text { Rapimán }\end{array}$ & Atenea & 2012 & Etnias & $\begin{array}{l}\text { Sistematización de } \\
\text { saberes indígenas }\end{array}$ \\
\hline $\begin{array}{l}\text { Docentes rurales, infancia y } \\
\text { adolescencia mapuche }\end{array}$ & $\begin{array}{l}\text { Guillermo } \\
\text { Williamson, } \\
\text { Isolde Pérez, } \\
\text { Guillermo } \\
\text { Collia, Francisca } \\
\text { Modesto \& } \\
\text { Nilsa Raín }\end{array}$ & Psicoperspectivas & 2012 & Etnias & $\begin{array}{l}\text { Opiniones sobre } \\
\text { la Educación } \\
\text { Intercultural } \\
\text { Bilingüe, ElB, } \\
\text { infancia y } \\
\text { adolescencia } \\
\text { mapuche en } \\
\text { contextos rurales }\end{array}$ \\
\hline
\end{tabular}




\begin{tabular}{|c|c|c|c|c|c|c|}
\hline & Título & Autor (es) & Revista & $\begin{array}{l}\text { Año de } \\
\text { publicación }\end{array}$ & Ámbito & $\begin{array}{l}\text { Foco/Tema/ } \\
\text { Ámbito }\end{array}$ \\
\hline & $\begin{array}{l}\text { Influencia del proceso de } \\
\text { enseñanza escolar fiscal en } \\
\text { la socialización de mujeres y } \\
\text { hombres aymara de la zona } \\
\text { altiplánica del norte de Chile }\end{array}$ & $\begin{array}{l}\text { Ana María } \\
\text { Carrasco } \\
\text { Gutiérrez \& Vivian } \\
\text { Gavilán Vega }\end{array}$ & $\begin{array}{l}\text { Estudios } \\
\text { Atacameños }\end{array}$ & 2012 & Etnias & $\begin{array}{l}\text { Rol de la educación } \\
\text { en la socialización } \\
\text { de género }\end{array}$ \\
\hline$\lesssim$ & $\begin{array}{l}\text { Migración y transición. Hijos } \\
\text { de inmigrantes de origen } \\
\text { latinoamericano en su } \\
\text { transición de la escuela al } \\
\text { trabajo en Chile }\end{array}$ & Kerstin Hein & $\begin{array}{l}\text { Si Somos } \\
\text { Americanos }\end{array}$ & 2012 & Inmigración & $\begin{array}{l}\text { Transición escuela- } \\
\text { trabajo }\end{array}$ \\
\hline 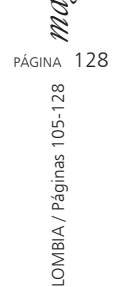 & $\begin{array}{l}\text { Sentido de la escuela para } \\
\text { niños y niñas mapuche en } \\
\text { una zona rural }\end{array}$ & $\begin{array}{l}\text { Ilich Silva-Peña, } \\
\text { Karina Bastidas } \\
\text { García, Luis } \\
\text { Calfuqueo } \\
\text { Tapia, Juan } \\
\text { Díaz Llancafil \& } \\
\text { Jorge Valenzuela } \\
\text { Carreño }\end{array}$ & $\begin{array}{l}\text { Polis, Revista } \\
\text { Latinoamericana }\end{array}$ & 2013 & Etnias & $\begin{array}{l}\text { Sentido de la } \\
\text { escuela para } \\
\text { alumnado mapuche }\end{array}$ \\
\hline 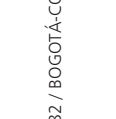 & $\begin{array}{l}\text { Construcción de conocimiento } \\
\text { mapuche y su relación con el } \\
\text { conocimiento escolar }\end{array}$ & $\begin{array}{l}\text { Segundo } \\
\text { Quintriqueo \& } \\
\text { Héctor Torres C. }\end{array}$ & $\begin{array}{l}\text { Estudios } \\
\text { Pedagógicos }\end{array}$ & 2013 & Etnias & $\begin{array}{l}\text { Sistematización de } \\
\text { saberes indígenas }\end{array}$ \\
\hline 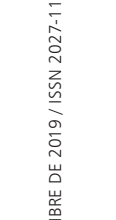 & $\begin{array}{l}\text { Prácticas y discursos } \\
\text { pedagógicos en Toconao. } \\
\text { Cultura, patrimonio e } \\
\text { interculturalidad }\end{array}$ & Ramiro Catalán & $\begin{array}{l}\text { Estudios } \\
\text { Atacameños }\end{array}$ & 2013 & Etnias & $\begin{array}{l}\text { Análisis del proceso } \\
\text { de implementación } \\
\text { del Programa } \\
\text { de Educación } \\
\text { Intercultural } \\
\text { Bilingüe, PEIB }\end{array}$ \\
\hline 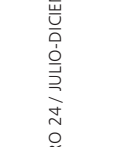 & $\begin{array}{l}\text { Las escuelas de la inmigración } \\
\text { en la Ciudad de Santiago. } \\
\text { Elementos para una educación } \\
\text { contra el racismo }\end{array}$ & $\begin{array}{l}\text { María Emilia } \\
\text { Tijoux }\end{array}$ & $\begin{array}{l}\text { Polis, Revista } \\
\text { Latinoamericana }\end{array}$ & 2013 & Inmigración & $\begin{array}{l}\text { Discursos y } \\
\text { prácticas escolares } \\
\text { hacia alumnado } \\
\text { inmigrante }\end{array}$ \\
\hline$\underset{\substack{\sum \\
\sum}}{\substack{\sum \\
\sum}}$ & $\begin{array}{l}\text { Inmigración y educación } \\
\text { intercultural en la formación } \\
\text { inicial docente }\end{array}$ & $\begin{array}{l}\text { Alejandra } \\
\text { Sánchez B., } \\
\text { Leandro Navas M. } \\
\text { \& Pablo } \\
\text { Holgado T. }\end{array}$ & $\begin{array}{l}\text { Estudios } \\
\text { Pedagógicos }\end{array}$ & 2013 & Inmigración & $\begin{array}{l}\text { Actitudes hacia } \\
\text { la inmigración de } \\
\text { estudiantes de } \\
\text { pedagogía }\end{array}$ \\
\hline
\end{tabular}

Fuente: elaboración propia 